\title{
Research on the Impact of Online Service Remedy on Customer Interactive Behavior in Virtual Brand Community
}

\author{
Hai Hu, Dongpu Li \\ Business School of Nanjing Normal University, Nanjing, China \\ Email: jadeldp1992@163.com
}

How to cite this paper: $\mathrm{Hu}, \mathrm{H}$. and Li, D.P. (2019) Research on the Impact of Online Service Remedy on Customer Interactive Behavior in Virtual Brand Community. Open Journal of Business and Management, 7, 135-150. https://doi.org/10.4236/ojbm.2019.71010

Received: December 10, 2018

Accepted: December 31, 2018

Published: January 3, 2018

Copyright $\odot 2019$ by author(s) and Scientific Research Publishing Inc. This work is licensed under the Creative Commons Attribution International License (CC BY 4.0).

http://creativecommons.org/licenses/by/4.0/

\section{(c) (i) Open Access}

\begin{abstract}
With the popularization and development of the internet, people's shopping, travel and other lifestyles have undergone tremendous changes. At the same time, the mode of maintaining customer relationship and creating enterprise and customer value has also changed. More and more enterprises transfer the channel of maintaining customer relationship and value creation from offline to online through virtual brand community, which not only breaks the limitation of time and space, but also provides better service for customers and improves customer loyalty. It is of great significance to realize value creation between enterprises and customers. Virtual brand community can not only help enterprises better understand the needs of customers, but also guide customers to participate in community interaction and better realize value creation. However, due to the virtuality and uncertainty of the Internet, the possibility of enterprises failing online services is greatly increased. If enterprises can't take timely remedial measures to alleviate customers' complaints and dissatisfaction, the negative emotions of customers will spread faster, have stronger targeting, and have wider impact. Therefore, the community will be reduced by influencing the customer interaction in the virtual brand community, thereby affecting the value sharing between enterprises and customers. Therefore, based on the regulatory focus theory, the impact of online service recovery on customer interaction behavior in virtual brand community is of great significance to realize value creation between enterprises and customers.
\end{abstract}

\section{Keywords}

Online Service Remedy, Customer Interactive Behavior, Regulatory Focus

\section{Introduction}

With the development of the Internet, more and more enterprises create the 
value of customers and enterprises by establishing virtual brand community. Therefore, maintaining the vitality of the community and improving the interaction behavior of customers in the community become the premise of value creation. When the enterprise fails in service, in the first time service remedy through the virtual brand community can soothe the customer's emotions and prevent the further spread of customer dissatisfaction; on the other hand, timely service remedy can make the customer feel valued, so it will improve the customer's satisfaction and product to the community. Polarity can effectively improve customer interaction in the community. Online service remedy through virtual brand community can effectively reduce the negative emotions of customers, improve the image of enterprises, promote customer interaction within the community, and lay the foundation for realizing customer participation and value creation. So the research has certain theoretical and practical significance to some extent.

\section{1) Theoretical Significance}

From a theoretical point of view, most of the previous studies on customer interaction in virtual brand community are aimed at explaining customer participation in value creation, or improving customer experience value and innovation behavior. However, few scholars consider how to improve customer interaction behavior from the perspective of service failure. This study attempts to establish a framework to explain customers' response to online service remediation in virtual brand community and how it affects customer interaction behavior. It also explores the moderating effects of different regulatory focus (promotional focus and defensive focus) on service remediation and customer interaction behavior. Is online service remedy able to make different customers more active in the virtual brand community interaction, so as to provide a basis for customer participation in value creation?

\section{2) Practical Significance}

The significance of virtual brand community is to provide customers with a more convenient service to improve customer loyalty to the brand, experience, and provide a shared platform to achieve value creation between customers and enterprises. Maintaining the vitality of virtual brand community is the premise of creating customer and enterprise value. When enterprises fail in service and fail to take appropriate measures to remedy it in time, it will affect the interaction of customers in the community, reduce the vitality of the community, and then affect customer participation in value creation in virtual brand community. At the same time, because customers with different regulatory focus respond differently to different remedial measures, it will also affect the occurrence of customer interaction behavior. This study explores the impact of online service remedy on customer interaction behavior. Considering that different regulatory focus has different impact on customer interaction behavior, this study can provide ideas for enterprises to improve the effectiveness of customer interaction behavior in virtual brand community, and has a certain practical significance. 


\section{Literature Review}

\subsection{Service Remedy}

Maxham (2001) defines service failure as errors or problems that consumers encounter when shopping or communicating with companies [1]; Chhal \& Devi (2015) believes that service failure occurs when the quality of service provided by enterprises fails to meet customers' psychological expectations [2]; Bitner (1990) classifies service failure into three categories: service delivery failure, and service delivery failure. Failure related to customer needs and requests, failure related to uninvited and requested employee behavior [3]. More importantly, service failure can lead to customer dissatisfaction and relationship collapse. Therefore, service recovery has always been a key and effective business strategy to win dissatisfied customers and maintain customer relationship. Service recovery refers to the response and process of service providers in solving the problems caused by service failure. Effective service recovery enables service providers to regain customer satisfaction and maintain customer loyalty, and is conducive to service providers to establish and maintain long-term good relations with customers and further expand the enterprise industry. Business, improve performance. Therefore, the importance and effectiveness of service remediation is very important for marketers and researchers to better understand. Especially in online shopping environment, there are more reasons for online service failure than offline service failure, such as: distribution process, packaging errors, website design, customer service, poor information, payment, security. Full, privacy and other issues, and because consumers in the online environment will experience more interaction and communication, consumers will know more about the relevant service information than in the offline shopping environment, and the requirements will be higher. Therefore, service providers may be more likely to make customers feel dissatisfied in the online shopping environment, and customers. It is possible to easily switch to other service providers by just a few clicks; however, most of the previous research on service remediation focused on limited structure and relationship, without considering the broader service relationship, especially the impact of service remediation in online shopping environment.

According to the existing service literature, service remedies are usually classified as material remedies and spiritual remedies. Material remedies refer to the provision of tangible compensation to customers through free services, refunds, gifts, discounts and coupons to reduce actual damage. Mental remedies refer to the use of apologies, transposition thinking and interpretation to correct service failure. Yang Xuecheng and Guo Guoqing (2009) believed that enterprises could provide material remedies (including cash compensation, gifts, discounts, etc.), spiritual remedies (including sincere apologies and explanations, friendly attitude of employees) and response speed (mainly referring to providing remedies) [4]. Response time is fast and timely and effective remedial measures are taken to control the service remedial actions of enterprises. Traditional service industry 
pays attention to the material compensation of service remedy, while online shopping not only pays attention to material remedy, presents gifts to customers by means of online marketing, but also pays attention to the spiritual remedy of customers, responds positively to customers' complaints, provides effective solutions to problems, and communicates with customers through chat tools. Apologize promptly and politely so that customers feel valued and meet their spiritual needs.

Therefore, this paper divides service remedy into three dimensions: material remedy, spiritual remedy and positive responsiveness, and sets up several items to measure these three dimensions. Combining with the research background of this paper, this research scale is moderately modified and data analysis is carried out.

\subsection{Customer Interaction Behavior}

When e-commerce is booming, members of the virtual brand community have a more free communication platform. Since then, the main method of customer information exchange is network interaction, and the start of e-commerce will change the channel of customer purchase behavior. The information exchange environment in the network is very different from that in the real society. Relying on the characteristics of the network itself, the network environment has broken the regional and class framework that limited human communication in the early period, and thus created a new interpersonal space. Quyong (2000) [5] and Jiang Huiwen (2009) [6] all think that the interaction in cyberspace shows some new characteristics: 1) Transspace; 2) Virtuality; 3) Symbolic or textual culture; that is, symbols and texts replace the traditional face-to-face communication. In cyberspace, the original direct speech symbols are replaced by visual text symbols; the expression that always shows in communication is replaced by image symbols; the traditional oral dialogues are transformed into more convenient and diverse electronic dialogues; and 4) de-socialization. In the real society, because of the existence of class, social attribute, region and other factors, communication has an insurmountable "gully", but in the network environment, this gully has been completely filled up. People can interact equally in a real sense; 5) Non-normative; network society can break through the limitations of time and space to create a virtual social living space, which transcends the limitations of geographical, national and cultural factors, thus making the original norms and orders in the real society face elimination. When interaction norms are missing, people's behavior will begin to become anomie. This will invisibly increase the risk and uncertainty of people's interaction. Wu Si et al. (2001) classified customer interaction in the network environment into two categories: social interaction and information exchange [7]. Kong Fanshi and Wang Huiping (2009) think that in the network community, based on the time characteristics of interpersonal interaction, they are divided into two forms: synchronic and asynchronous interaction, and the dimensions of interpersonal interaction are 
divided into: frequency of interpersonal interaction; depth of interpersonal interaction; emotional power of interaction; and the amount of information exchange among members; the feeling of interpersonal interaction environment; the form of interpersonal interaction [8]. Li Zhilan (2015) distinguishes customer interaction from word-of-mouth research [9]. She believes that the main differences between customer interaction and word-of-mouth research lie in different subjects, different places and different contents. (Zhao Jianbin, Jing Fengjie, Yu Ying, 2015) According to the characteristics of virtual brand community, customer interaction can be divided into two categories: information interaction for knowledge acquisition; information exchange for products, enterprise information and so on [10]. In this way, we can understand the product or market; the second type is interpersonal interaction. The purpose of this interaction is to enhance the emotional exchange between the two sides, so as to gain respect or care from the other side. Yang Rui (2017) concluded that customer interaction in virtual brand community includes five dimensions: information interaction, positive emotional communication, self-image recognition, violation of social interests and false information [11].

To sum up, there are some similarities and differences between the customer interaction under the network environment and that under the traditional environment. The similarities lie in the information or feeling communication process around the brand; the differences lie in the traditional customer interaction is "face-to-face" communication and communication; and in the network environment, the customer interaction is "face-to-face" communication and communication. Customer interaction is a process of information or experience exchange that is replaced by symbols or texts through the Internet as the main medium.

Based on the above literature review and the characteristics of this study, this paper uses the classification results of customer interaction (Zhao Jianbin, Jing Fengjie, Yu Ying, 2015) to divide customer interaction into two categories: the first is information interaction, mainly about product or service information, market information exchange, etc. Emphasize the exchange of practical information; the second type is interpersonal interaction, mainly the inner emotional communication between members, mainly focusing on emotional communication and communication.

\subsection{Regulatory Focus}

As early as 1967, Eysenck proposed that the difference of personality traits is caused by the difference of brain structure and brain function. He also divided personality traits into extroversion and emotionality [12]. Since then, Gray (1987) has also proposed that personality traits can be divided into impulsive and anxious tendencies according to dimensions [13]. The differences in personality traits can lead to different behaviors of individuals. Later, the scholar Higgins (1997) sorted out and analyzed the previous research and got the concept of 
regulatory focus theory. He pointed out that different regulatory focus will lead to different behavior patterns [14]. He believes that everyone has two different regulatory systems, one is Promotion Focus, which means that individuals tend to pay attention to rewards and exercise themselves in advance, so that they focus on positive goals. Individuals with promotional regulatory focus are pursuing themselves, caring about expectations and vision. The other is prevention Focus, which means that individuals tend to prevent punishment in advance, which makes them focus on negative goals. This kind of individuals show their pursuit of duty, responsibility and obligation.

Domestic research on the theory of regulatory focus started relatively late, and only a few scholars have studied it in recent years. Compared with foreign scholars' research on the theory of regulatory focus, domestic scholars' research based on the theory put forward by foreign scholars demonstrates the inherent mechanism and exploratory nature of the theory of regulatory focus. Shi Qing (2010, 2011) used samples from different units to carry out empirical tests [15] [16]. The research shows that the theory of regulatory focus and the characteristic regulatory focus. Point scale is adapted to Chinese cultural background, and its research shows the regulatory effect of focal point adjustment. Li Lei and Shang Yufan (2011) introduced individual focus and group focus into the research model chapter in the research on the influence of leadership on employee creativity, and pointed out that the adjustment focus played a mediating role [17]. At the same time, Li Lei, Shang Yufan and Xi Youmin (2011) [18] pointed out through empirical research that, compared with the leadership Defense Language framework, the leadership promotion language framework can promote subordinates' work attitude, and vice versa. Later, Li Lei, Shang Yuvan and Xi Youmin (2012) [19] further introduced the two dimensions of regulatory focus theory (trait focus and situational focus) into the relationship between leadership speech framework and subordinate creativity. Empirical research with students as samples shows that subordinate situational focus plays a part of mediating role, while idiosyncratic focus regulates the relationship between situational focus and subordinate creativity, which further reveals the deep-seated mechanism of regulatory focus theory.

\section{Research Hypothesis}

\subsection{The Impact of Online Service Remediation on Customer Interactive Behavior}

According to the principle of reciprocity of social exchange theory, the relationship formed in the process of communication is a kind of exchange relationship. The individual's reward behavior is based on the individual's response to the subject who gives himself value. People who perceive benefits are more likely to produce reward behavior. The social relationship between enterprises and customers is an exchange relationship. In the virtual brand community, only when the enterprise gives the expected benefits to the customers, the customers will participate in the construction of the community. When customers reflect the 
problems of products or services through the virtual brand community, on the one hand, it is to solve the problems they encounter in the process of using products and experiential services, on the other hand, it is expected that enterprises will compensate themselves by this way to make up for the problems they encounter in the process of using products and experiential services. This kind of compensation can be both material and spiritual. Price et al. (1999) believed that when employees of online stores gave customers certain material benefits, they would establish a trust relationship with customers, so that customers would support and support online stores out of the principle of reciprocity [20]. By communicating with the community staff (enterprises) and feedback their own problems, the community takes certain online material remedial measures, such as giving customers coupons, cash compensation, and discounts when repurchasing, which will satisfy customers' expectations, so that customers will invest more energy in the virtual brand community to improve customer interaction. Spiritual remedy refers to the remedy that uses apology, transposition thinking and explanation to correct the problems caused by service failure and improve customer satisfaction. Rosenbaum and Massiah (2007) [21] surveyed 207 fitness members and found that emotional support had a significant positive effect on customer interaction behavior, especially when customers received social emotional support, they were more willing to show reward behavior. Virtual brand community staff (enterprises) take spiritual remedial measures to customers, which will make customers feel the fairness of corporate services, but also improve the customer's perception of presence, and close the psychological distance between customers and employees (enterprises). At this time, customers are more willing to take reciprocal behavior, that is, interactive behavior. Response speed refers to the quick response time to provide remedies and the timely and effective adoption of remedial measures. When community workers can respond to customers' problems in a timely manner and take measures, they will make customers feel respected and their needs satisfied, and enhance their satisfaction will make customers more active in the virtual brand community. Therefore, on this basis, this paper puts forward the following assumptions:

H1: Online Service Remediation of Virtual Brand Community Promotes Customer Interactive Behavior

H1a: Online Material Remedy Promotes Information Interaction

H1b: Online Material Remedy Promotes Interpersonal Interaction

H1c: Online Spiritual Remedy Promotes Information Interaction

H1d: Online Spiritual Remedy Promotes Interpersonal Interaction

H1e: Online Response Speed Forward Promoting Information Interaction Behavior

H1f: Online Response Speed Promotes Interpersonal Interaction

\subsection{The Regulating Function of Regulating Focus}

Chen Si et al. (2016) pointed out that the focus of regulation would affect the in- 
dividual's information processing and behavioral orientation, that is, the individual's preference for internal self-psychological regulation arising from the external environment, which would affect the individual's cognition of the external situation, thus causing the difference of individual's actual action under the influence of behavioral motivation [22]. Individuals with promotional adjustment focus are more concerned about whether they can achieve positive goals. They are more concerned about whether they can achieve their career and get rewards. They often adopt the way and strategy of promoting progress to approach their goals. They dare to face up to difficulties when solving problems and difficulties and achieve the positive goals they set. Individuals with defensive focus think more about their own responsibilities and obligations, pay more attention to whether they will suffer losses or failures. Commonly used defensive methods and strategies are close to the goal and pursue a stable state. Therefore, customers with different regulatory focus will show different behaviors when facing remedial measures of virtual brand community.

According to Social Information Processing Theory, the environmental factors around individuals greatly influence their attitudes and behaviors. When customers feedback to the virtual brand community (enterprise) about service failure, the remedial measures taken by staff (enterprise) will affect the follow-up behavior and performance of customers. Li Xiyuan et al. (2018) research shows that regulation focus affects the individual's processing of information, leading to different behavioral orientations [23]. According to the human instinct of "seeking profits and avoiding disadvantages", for the customers with promotional focus, after getting the corresponding service remedies, the customers will be satisfied in their hearts, and then pay more attention to whether to realize self-worth in the virtual brand community. Therefore, for the customers with promotional focus, online service remedial measures of virtual brand community can promote customer interaction. For customers with defensive focus, the purpose of feedback service or product problems to virtual brand communities (enterprises) is to get corresponding remedies. When community workers (enterprises) take timely remedial measures to customers' problems, customers have been compensated, and refuse to participate in community interaction will not be customers. It does harm. Therefore, for customers with defensive focus, online service remedial measures of virtual brand community can inhibit customer interaction. Based on the above analysis, the following assumptions are put forward:

H2: Regulating Focus has a moderating effect on the relationship between online service recovery and customer interaction behavior in virtual brand community.

H2a: Promotional Focus moderates the relationship between online service recovery and customer interaction behavior in virtual brand communities.

H2b: Defensive Focus Moderates the Relationship between Online Service Remedy and Customer Interactive Behavior in Virtual Brand Community. 


\section{Variable Measurement and Questionnaire Design}

\subsection{Online Service Remedy}

In terms of the dimensions of the service recovery scale, this paper decides to adopt the research scale proposed by Forbes (2005), spiritual recovery scale developed by Hsing (2012), Chang Yaping (2009), and positive response scale developed by Forbes (2005).

\subsection{Customer Interaction Behavior}

Based on the characteristics of virtual brand community research and the research results of scholars at home and abroad, this paper divides the customer interaction behavior in virtual brand community into two dimensions: information interaction and interpersonal interaction. Information interaction refers to the communication of product information, enterprise information, brand information and market information between customers and customers in the community; interpersonal interaction refers to the emotional communication between customers in the community.

\subsection{Regulatory Focus}

Regulatory focus is divided into two dimensions: facilitative focus and defensive focus. The measurement of regulatory focus in this study is based on Lockwood, Jordan and Kunda scales, combined with the characteristics of regulatory focus research and the research achievements of scholars at home and abroad, and on this basis, translation is carried out in combination with the basic situation in China. Some modifications were made and eight items were finally determined.

\subsection{Control Variables}

Based on the research objectives and research models, this paper chooses six variables, including gender, age, educational background, occupation, monthly income and age of online shopping, as the control variables of this study. The use of virtual variables to deal with gender, 1 for men and 2 for women; Age is measured by the actual age of the respondents; Monthly income is measured by the actual monthly income of the respondents; Education is measured by the actual education level of the respondents; Occupations are classified according to categories; Online purchase age is divided into four levels from less than 6 months to more than 3 years.

\section{Empirical Analysis}

\subsection{Data Collection}

This paper takes Apple, Huawei, millet and other electronic products users as the subjects of the survey, using online and offline questionnaires to obtain data and conduct a questionnaire survey. Off-line questionnaires are sent out by intercepting and investigating social figures in large supermarkets in Nanjing, and 
investigating some teachers and students with the help of tutors and students around them. On-line questionnaires are sent through the Internet to close friends and their friends around them to fill in, which have been filled in by sending questionnaires. The difficulties encountered in the process were explained by the author himself, and eventually returned through electronic questionnaires. The survey lasted more than three months. A total of 300 questionnaires were sent out, 289 were recovered, 16 were rejected and 273 valid questionnaires were recovered, which are 165 online questionnaires and 108 offline questionnaires. The recovery rate of the questionnaires was $96.33 \%$, and the effective recovery rate was $94.4 \%$.

\subsection{Sample Characteristic Description}

In the questionnaire on the relationship between online service recovery and customer interaction behavior, background information mainly includes gender, age, education level, occupation, monthly income and the relevant information about the use of electronic products. Among the 273 valid questionnaires collected, the gender distribution was more uniform, with women accounting for $53.8 \%$ of the total sample and men accounting for $46.2 \%$ of the total sample. In terms of age distribution, the respondents of all ages are involved. On the whole, the proportion of young people is relatively large and concentrated in the $21-30$ years old, because young people are very active in the virtual brand community. In terms of monthly income distribution, less than $1 \%$ is below 1000 yuan, $46.2 \%$ is between 1001 and 2000 yuan, and 30.8\% is between 2001 and 5000 yuan. In terms of culture, undergraduate degree is the main factor, accounting for $69.5 \%$ of the total sample, $20.5 \%$ of the samples are below senior high school and junior college, and $10 \%$ of the samples are above master's degree. In terms of occupational distribution, people from all walks of life, mainly students, accounting for $36.7 \%$ of the total sample. In terms of the distribution of years of using electronic products, the majority of employees are $5-10$ years, accounting for $43.6 \%$.

\subsection{Result Analysis}

After calculating the mean of variables, this paper uses the mean of relevant variables to test the linear correlation between online service recovery of independent variables, adjustment of variable focus and customer purchase behavior of dependent variables. Table 1 reveals the results of the correlation analysis in this paper. It shows that the dimensions of online service recovery are positively correlated with customer interaction behavior and are basically significant, and have no correlation with regulatory variable focus. The correlation coefficient between online material remedy and information interaction is 0.334 , the correlation coefficient between online mental remedy and information interaction is 0.428 , the correlation coefficient between online response speed and information interaction is 0.318 , the correlation coefficient between online material remedy 
Table 1. Analysis of variables.

\begin{tabular}{|c|c|c|c|c|c|c|c|}
\hline Variable & $\begin{array}{l}\text { Physical } \\
\text { remediation }\end{array}$ & $\begin{array}{l}\text { Spiritual } \\
\text { remediation }\end{array}$ & $\begin{array}{c}\text { Response } \\
\text { speed }\end{array}$ & $\begin{array}{l}\text { Accelerative } \\
\text { focus }\end{array}$ & $\begin{array}{l}\text { Defensive } \\
\text { focus }\end{array}$ & $\begin{array}{l}\text { Informative } \\
\text { interaction }\end{array}$ & $\begin{array}{c}\text { Interpersona } \\
\text { interaction }\end{array}$ \\
\hline Physical remediation & 1 & & & & & & \\
\hline Spiritual remediation & $0.88^{* * *}$ & 1 & & & & & \\
\hline Response speed & $0.85^{\star * *}$ & $0.826^{\star * *}$ & 1 & & & & \\
\hline Accelerative focus & $0.845^{\star * *}$ & $0.809^{* * *}$ & $0.795^{\star * *}$ & 1 & & & \\
\hline Defensive focus & 0.064 & 0.086 & 0.106 & 0.093 & 1 & & \\
\hline Informative interaction & $0.334^{\star * *}$ & $0.428^{\star * *}$ & $0.318^{\star * *}$ & $0.274^{*}$ & $0.556^{* * *}$ & 1 & \\
\hline Interpersonal interaction & $0.274^{\star * *}$ & $0.412^{* * *}$ & $0.307^{* * *}$ & $0.574^{* * *}$ & $0.683^{* * *}$ & $0.436^{* * *}$ & 1 \\
\hline
\end{tabular}

and interpersonal interaction is 0.274 , and the correlation coefficient between online material remedy and interpersonal interaction is 0.412 . The correlation coefficient between online material remedy and interpersonal interaction was 0.307. However, there is a significant positive correlation between regulatory focus and customer interaction behavior, so the hypothesis has been proved preliminarily.

Table 2 shows that after adding control variables, online service recovery still has a positive relationship with customer interaction behavior, which shows that the independent variables added in model 2 have a better explanatory power to dependent variables and pass the $1 \%$ significance level test, so it is assumed that H1 can be established. The results show that material remedy, mental remedy and response speed of online service remedy have a positive impact on customer interaction behavior and pass the significance test as shown in Table 3. The positive effect of spiritual remedy on customer interaction behavior is the greatest, and the regression coefficient is 0.362 , which shows that the spiritual remedy of online service remedy has the greatest impact on customer interaction behavior; the second is the impact of material remedy on customer interaction behavior. The regression coefficient is 0.327 , which passes the $5 \%$ significance level test. Therefore, the three sub-hypotheses of $\mathrm{H} 1 \mathrm{a}, \mathrm{H} 1 \mathrm{~b}$ and $\mathrm{H} 1 \mathrm{c}$ all pass the hypothesis test.

According to the regression variance determination coefficient of Table 4 above, when the product term of online service recovery and regulation focus is added to the regression model, the symbol of product term is the same as that of independent variable, which shows that regulation focus can enhance the impact of online service recovery on customer interaction behavior. Suppose H2 is proved. From Table 5, we can see that online service recovery still positively affects consumers' willingness to buy online after adding various dimensions of regulatory focus (promotional focus, defensive focus) and their interaction items. Moreover, the regression coefficients of interaction items between online service recovery and regulatory focus (promotional focus, defensive focus) are positive, indicating that the adjustment changes. Quantity regulation focus restrains 
Table 2. Result of regression analysis of online service remediation and customer interaction behavior.

\begin{tabular}{cccc}
\hline variable & Normalized coefficient & $\mathrm{T}$ & Significance \\
\hline Constant & 6.581 & 5.638 & 0.000 \\
Online service remediation & 0.340 & 2.172 & 0.037 \\
Gender & 0.182 & 1.148 & 0.259 \\
Monthly income & 0.089 & 0.558 & 0.580 \\
F & & 3.1 & \\
Adj $^{2}$ & & 0.073 & \\
\hline
\end{tabular}

Table 3. The results of regression analysis of regulatory focus in various dimensions of online service recovery.

\begin{tabular}{cccc}
\hline variable & $(1)$ & $(2)$ & $(3)$ \\
\hline Constant & $6.417^{* * *}(5.593)$ & $6.694^{* * *}(5.746)$ & $6.352^{* * *}(5.531)$ \\
Physical remediation & $0.327^{* *}(2.085)$ & & \\
Spiritual remediation & & $0.362^{* *}(2.330)$ & \\
Response speed & & & $0.313^{*}(1.986)$ \\
Gender & $0.166(1.041)$ & $0.199(1.258)$ & $0.159(0.992)$ \\
Monthly income & $0.099(0.621)$ & $0.096(0.608)$ & $0.088(0.547)$ \\
F & 2.873 & 2.945 & 2.777 \\
Adj $\mathbf{R}^{2}$ & 0.064 & 0.09 & 0.055 \\
\hline
\end{tabular}

Table 4. Regression analysis results of regulatory focus effect test.

\begin{tabular}{ccc}
\hline variable & $(1)$ & $(2)$ \\
\hline Constant & $3.809^{* * *}(7.557)$ & $4.122^{* * *}(4.145)$ \\
Online service remediation & $0.387^{* * *}(3.421)$ & $0.387^{* * *}(3.336)$ \\
$\begin{array}{c}\text { Online Service Remediation* } \\
\text { Regulatory focus }\end{array}$ & $0.326^{* * *}(2.896)$ & $0.324^{* * *}(2.804)$ \\
Regulatory focus & $0.587^{* * *}(5.206)$ & $0.577^{* * *}(4.843)$ \\
Gender & & $0.037(0.310)$ \\
Monthly income & & $0.031(0.260)$ \\
F & 14.697 & 8.377 \\
Adj $\mathbf{R}^{2}$ & 0.520 & 0.493 \\
\hline
\end{tabular}

Table 5. Fractional dimension test results of regulatory focus regulation effect.

\begin{tabular}{ccc}
\hline variable & $(1)$ & (2) \\
\hline Constant & $4.001^{\star * *}(3.997)$ & $4.147^{* * *}(4.009)$ \\
Online service remediation & $0.585^{* * *}(4.788)$ & $0.554^{* * *}(4.545)$ \\
Accelerative focus & $0.396^{\star * *}(3.325)$ & \\
Online Service Remediation* & $0.297^{* * *}(2.494)$ & \\
Accelerative Focus & & \\
\hline
\end{tabular}


Continued

\begin{tabular}{ccc}
\hline $\begin{array}{c}\text { Defensive focus } \\
\text { Online Service Remediation } \\
\text { Defensive Focus } \\
\text { Gender }\end{array}$ & $-0.362^{* *}(-3.039)$ \\
Monthly income & $0.015(0.125)$ & $-0.293^{* *}(-0.247)$ \\
F & $0.053(0.621)$ & $0.059(0.479)$ \\
AdjR $^{2}$ & 7.676 & $0.022(0.183)$ \\
\end{tabular}

Note: “***” means correlation at $1 \%$ (bilateral) significance level, “**” means correlation at $5 \%$ (bilateral) significance level and “*” means correlation at $10 \%$ (bilateral) significance level.

the negative impact of online negative reviews on online purchasing intention. In summary, the four sub-hypotheses A and B in $\mathrm{H} 2$ have passed the hypothesis verification.

\section{Research Findings}

Aiming at the relationship between online service remedy and customer interaction behavior, this paper first examines the significant positive correlation between the three dimensions of online service remedy and the two dimensions of customer interaction behavior through correlation analysis. Then in the regression analysis, the effects of online material remedy, mental remedy and response speed on information interaction and interpersonal interaction behavior have passed the significant test, and their respective regression coefficients are positive, which shows that the dimensions of online service remedy have significant positive effects on the dimensions of customer interaction behavior. It is assumed that H1a, H1b, H1c, H1d, H1e and H1f are supported. Therefore, both theoretical and empirical analyses in this paper show that online service recovery does have an important impact on customer interaction behavior.

The product coefficient of online service recovery and facilitative focus has passed the significant test, which shows that facilitative focus has a moderating effect between online service recovery and customer interaction behavior. That is to say, the promotional focus positively promotes the impact of online service recovery on customer interaction behavior, and $\mathrm{H} 2 \mathrm{a}$ is assumed to be valid. The product term coefficients of online service recovery and defensive regulatory focus passed the significant test, indicating that defensive regulatory focus has a moderating effect between online service recovery and customer interaction behavior. That is to say, defensive focus negatively inhibits the impact of online service recovery on customer interaction behavior, and $\mathrm{H} 2 \mathrm{~b}$ is assumed to be valid.

\section{Marketing Proposals}

\subsection{Strengthen Online Service Remediation and Make Rational Use of Remedial Measures}

Online service remediation will have an important impact on customers' inte- 
raction behavior in virtual brand community, and then affect the value creation of customers and enterprises. If the virtual brand community staff (enterprises) do not take any remedial measures or remedial measures to service failure, the customer's demands can not be satisfied, which will greatly affect the trust and loyalty of customers to the enterprise. Therefore, for online service remediation of service failure, virtual brand community (enterprises) should be given enough attention.

\subsection{Strengthen the Level of Mental Remedy and Communicate Well with Consumers}

When solving the problem of customer service failure, virtual brand community staff should take it seriously. They should not only patiently explain the reasons for service failure to customers, but also listen carefully to customers' demands and communicate with customers in detail. Only in this way can the trust between customers and enterprises be increased, and at the same time it will be reduced customers' misunderstanding of the enterprise. If customers' service failures are met spiritually, they will take more initiative to participate in the activities of the virtual brand community. This is a win-win situation for both enterprises and customers.

\subsection{Improve the Service Level of Community Workers and the Efficiency of Service Recovery}

Virtual brand community should improve the service level of staff, be able to timely remedy according to the different situation of customers, and improve the efficiency of service remedy. The community can sort out the problems of customer feedback and sort out the solutions in advance according to different types of problems, so that when similar problems arise, the staff of the community can respond to the problems in time. In this way, the customers will feel the professionalism of the staff and increase their trust in the community. On the other hand, timely response will also make customers feel valued, which will increase their loyalty to the community. Professional service ability and efficiency of staff will greatly improve the customer's sense of social presence, so they will invest more time and energy in the community, and greatly improve the occurrence of customer interaction behavior. At the same time, virtual brand community should also give staff some autonomy, flexible response to some special problems, timely remediation of customers, which will greatly improve the efficiency of service recovery, but also enhance customer trust in the community. This will play a positive role in improving customer interaction behavior and realizing value creation between customers and enterprises.

\subsection{To Create a Good Community Interaction Environment for Different Focus Customers}

Enterprises should adopt different service remedial measures according to the customers with different adjustment focus when carrying out service remediation. 
Virtual brand community should create a good community atmosphere to ensure that customers with defensive focus also participate in community interaction. The community can publicize some activities in the community when it makes service remedies for defensive focus customers, so that they can lower their alert and feel good will in participating in community interaction. At the same time, the virtual brand community should optimize the community interface, so that customers feel comfortable in the process of participating in the interaction, which will also reduce the defense of defensive focus customers, and thus can improve the customer's interactive participation. For the customers with promotional focus, the community should timely remedy online service and timely resolve their feedback on service failure. In this way, the customers with promotional focus will feel satisfaction and achievement in the process of feedback with the community, and then will actively engage in community interaction.

\section{Conflicts of Interest}

The authors declare no conflicts of interest regarding the publication of this paper.

\section{References}

[1] Maxham III, J.G. and Netemeyer, R.G. (2001) A Longitudinal Study of Complaining Customers' Evaluations of Multiple Service Failures and Recovery Efforts. Journal of Marketing, 66, 57-71. https://doi.org/10.1509/jmkg.66.4.57.18512

[2] Chhal, D. (2015) Effects of Complaint Behaviour and Service Recovery Satisfaction on Consumer Intentions to Repurchase on the Internet. Internet Research, 24, 608-628.

[3] Wen, B.Y. and Chi, C.G. (1990) Examine the Cognitive and Affective Antecedents to Service Recovery Satisfaction. International Journal of Contemporary Hospitality Management, 25, 306-327. https://doi.org/10.1108/09596111311310991

[4] Yang, X.C., Guo, G.Q., Wang, X.F. and Chen, D. (2009) The Influence of Controllable Features of Service Recovery on Customer Word-of-Mouth Communication Intention. Management Review, 21, 56-64.

[5] Qu, Y. (2000) The New Characteristics of Interpersonal Interaction in Internet. Society, 6, 100-110.

[6] Jiang, H.W. (2009) A Brief Analysis of the Differences of Interpersonal Interaction Modes between Virtual Society and Real Society. Journal of Ningbo Radio and Television University, 13, 78-96.

[7] Wu, S., Ling, Y.H. and Wang, L. (2001) Research on the Relationship among Interaction, Trust and Willingness to Participate in Virtual Brand Community. Intelligence Journal, 5, 184-202.

[8] Kong, F.S. and Wang, H.P. (2009) Research on the Relationship between Interpersonal Interaction and Online Consumption Behavior in Virtual Communities. Ways of Operation, 23, 15-30.

[9] Li, Z.L. (2015) Review and Prospect of Research on Customer Interaction. Foreign Economy and Management, 15, 44-66.

[10] Zhao, J.B., Jing, F.J. and Yu, Y. (2015) The Relationship between Customer Interac- 
tion, Psychological Contract and Loyalty in Brand Community. Economic Latitude, 4, 33-54

[11] Yang, R. (2017) Exploration of Structural Dimensions of Customer Interaction in Virtual Brand Community and Development of Measurement Scale. Journal of Management, 6, 70-99.

[12] Eysenck, H.J. (1967) A Model of Creativity and Innovation in Organizations. Research in Organizational Behavior, 10, 123-167.

[13] Grey, R.H. (1987) Organizational Justice: Yesterday, Today, and Tomorrow. Journal of Management, 16, 399-432.

[14] Higgins, E.T. (1997) Beyond Pleasure and Pain. American Psychologist, 52, 1280-1300. https://doi.org/10.1037/0003-066X.52.12.1280

[15] Shi, Q. and Gong, H.T. (2010) The Moderating Effect of Idiosyncratic Regulatory Focus on the Effectiveness of Transformational Leadership Behavior. Statistics and Decision-Making, 16, 181-183.

[16] Shi, Q. (2010) Theoretical and Empirical Research on the Mechanism of Leadership Behavior Affecting Employees' Work Attitudes-From the Perspective of Employees' Psychological Motivation. PhD Dissertation, Southwest Jiaotong University, Chengdu.

[17] Li, L., Shang, Y. and Xi, Y. (2011) Leadership Language Framework, Subordinate Traits Regulating Focus and Subordinate Working Attitude. Management Science, 24, 21-30.

[18] Li, L. and Shang, Y.-V. (2011) Research on the Mechanism of Leadership's Impact on Subordinate Creativity Based on the Adjustment Focus Theory. Nankai Management Review, 14, 4-11.

[19] Li, L., Shang, Y. and Xi, Y. (2012) Research on the Impact of Leadership Language Framework on Subordinate Creativity Based on Regulatory Focus Theory. Scientific Research Management, 33, 127-137.

[20] Price, L.L. and Arnould, E.J. (1999) Commercial Friendships: Service Provider-Client Relationships in Context. Journal of Marketing, 63, 38-56.

[21] Rosenbaum, M. (2007) When Customers Receive Support from Other Customers: Exploring the Influence of Inter-Customers Social Support on Customer Voluntary Performance. Journal of Service Research, 9, 257-270. https://doi.org/10.1177/1094670506295851

[22] Chen, S., Li, X. and Lu, X. (2016) Research on Motivation of Employee Voice Behavior Based on the Role of Focal Adjustment. Journal of Management, 13, 551-559.

[23] Li, X., Yan, D. and Wang, L. (2018) Paradoxical Leadership's Impact on Employees' Advice Behavior: The Role of Psychological Security and Focus Adjustment. Enterprise Economy, No. 3, 102-109. 